A $R$ R T T I I C C U L L O

$\begin{array}{lllllllll}R & E & F & L & E & X & I & O & N\end{array}$

\title{
LAS ZONAS GRISES DE LA INTERCULTURALIDAD EN SALUD
}

\author{
THE GRAY AREAS OF INTERCULTURALITY IN HEALTH
}

\author{
Por: Mario Siddhartha Portugal Ramírez*
}

* Sociólogo por la Universidad Autónoma Gabriel René Moreno (Bolivia) y obtuvo una maestría en sociología por la Facultad Latinoamericana de Ciencias Sociales (FLACSO), cede Ecuador. En la doctorando del programa Global Governance and Human Security de la Universidad de Massachusetts Boston. E-mail: mariosiddhartha@yahoo.com

\begin{abstract}
RESUMEN
El presente trabajo muestra el surgimiento de un espacio de excepción, de límites espaciales y simbólicos, denominado zona gris, donde se hace posible el desarrollo las medicinas populares urbanas. A partir de un estudio de caso, la medicina con hierbas medicinales en los mercados de Quito (Ecuador), se muestra que estos espacios emergen de una interculturalidad despolitizada y de una interculturalidad en salud que subordina a las medicinas tradicionales a un modelo biomédico hegemónico, omitiendo a las medicinas populares urbanas. Sin embargo, esta omisión les da la posibilidad de crear, transformarse y resistir subrepticiamente.
\end{abstract}

Palabras clave: interculturalidad, salud, medicina popular urbana, zona gris, modelo médico.

\begin{abstract}
The present work shows the emergence of a space of exception, of spatial and symbolic limits, called gray zone, where urban popular medicines are made possible. From a case study, medicine with medicinal herbs in the markets of Quito (Ecuador), shows that these spaces emerge from a depoliticized Interculturality and an Interculturality in health that subordinates traditional medicines to a biomedical model hegemonic, omitting popular urban medicines. However, this omission gives them the ability to create, transform and surreptitiously resist.
\end{abstract}

Keywords: interculturality, health, urban popular medicine, gray area, medical model.

\section{Introducción}

1 presente artículo es una reflexión sobre las "zonas grises" de la
interculturalidad en salud, es decir, aquel espacio formado por límites
espaciales y simbólicos que surgen como efecto de la desatención de
algunas tradiciones médicas por las políticas públicas en salud. Un estudio
de caso, la medicina popular urbana con hierbas de los mercados de Quito
(Ecuador), me permitirá explorar por qué surge este fenómeno que cobra
características particulares al desarrollarse en un ámbito urbano.


El documento tiene cuatro secciones. Primero presento los rasgos de la medicina popular urbana en los mercados quiteños. Aquí el lector conocerá cómo surge, quien la ejerce y cómo lo hace. La segunda parte habla sobre la interculturalidad en salud y cómo se consolida en la relación Estado-medicinas tradicionales. Aquí sostengo que el modelo médico hegemónico esencializa lo ancestral e impone sus axiomas y criterios de validación. En la tercera parte, reconceptualizo una zona gris, describiendo sus características. Finalmente, en las conclusiones desarrollo el potencial de las zonas grises como acciones creativas, no tradicionales y no violentas de resistencia.

\section{La carta visible: la medicina popular urbana en los mercados de Quito}

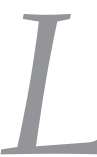

a carta robada de Edgar Allan Poe narra la historia de una epístola hurtada para extorsionar a su propietario, un influyente político francés. La policía parisina descubre que el ladrón fue un ministro, pero les resulta imposible hallar el documento. Desesperado, el jefe de policía acude a su amigo, el afamado detective Dupin, para que le colabore a resolver el misterio. Para sorpresa de todos, el hábil investigador halla la carta sin problema alguno y demuestra a la policía que la misiva extraviada siempre estuvo sobre la repisa de la chimenea, a la vista de todos, junto a otros papeles. La moraleja de Poe, si es que quiso hacer una, es que muchos hechos son omitidos por la poca habilidad para observar o incluso como un acto negligente deliberado.

Utilizaré la narración de Poe como metáfora para ilustrar la posición de algunas tradiciones médicas dentro de la interculturalidad en salud. Varios países en América Latina cuentan con legislación específica para promover que sus sistemas públicos de salud incluyan a las medicinas tradicionales, lo cual les ha llevado a crear instituciones específicas y a implementar políticas públicas. Ecuador, por ejemplo, cuenta con una Dirección de Salud Intercultural dentro del Ministerio de Salud Pública y la salud intercultural se menciona en su Constitución, su Plan Nacional del Buen Vivir y otra legislación específica. Sin embargo, existen medicinas que son utilizadas a diario por cientos de personas, pero que son ignoradas por todo este acervo legal. Una de ellas es la medicina popular basada en hierbas y otras terapias que puede hallarse en varios mercados de la ciudad de Quito en Ecuador.

Entre el año 2014 y 2015, realicé una etnografía en los mercados de Quito con las mujeres llamadas "hierberas", aunque este término es impreciso puesto que sus terapias incluyen elementos para sus curaciones como velas, 
1 Conejillo de indias.

2 Una bebida alcohólica hecha de caña de azúcar. incienso, perfumes o la "limpia" con cuy ${ }^{1}$. Un año antes, estaba de compras junto a una compañera de la universidad en el mercado San Roque, ubicado en el tradicional barrio del mismo nombre, cerca de los "puestos" o espacios destinados a las hierbas medicinales. Nos acercamos con curiosidad cuando vimos pequeñas cajas de colores con nombres tan variopintos como "vela del estudiante", "perfume ven a mí, ven a mí" o "extracto quitahechizos". Más allá colgaba un pequeño cartel negro con letras doradas que decía "cura el espanto". El anuncio pertenecía a Gloria Chicaiza, hierbera desde su adolescencia.

Gloria nos preguntó lo que queríamos comprar y antes de que pudiésemos contestar nos ofreció varias hierbas mientras enunciaba sus propiedades: "chuquiragua para el colesterol alto y limpiar la sangre", "matico para los granos", "casamarucha buena para la próstata", "taraxaco para purificar su sangre" "la ortiga para el reumatismo...". Le comenté que tenía dolor de espalda y ella enseguida comenzó a hacerme preguntas tan heterogéneas como a qué me dedicaba, si tenía familia, en qué lugar exactamente estaba la molestia, si tenía alguna otra preocupación y otras preguntas por el estilo.

Le dije a Gloria que éramos estudiantes, por lo cual pasábamos horas sentados, leyendo y escribiendo delante de una computadora. De inmediato me dio un primer diagnóstico: estrés por el estudio que acumulábamos como una "mala energía" (por eso el dolor). La solución para aliviarnos de aquella carga perjudicial para nuestros cuerpos y mentes era hacernos una "limpia" con hierbas. Movido por la curiosidad, acepté hacerme la terapia y me pidió que entrara al "puesto". El espacio era en realidad una división hecha con una tela en cuyos costados había anaqueles donde se almacenaban hierbas secas y otros productos. Pequeños cromos con la imagen de Jesucristo, la virgen y santos colgaban por doquier, además de un rosario de cuentas blancas plásticas que remataban en un crucifijo metálico. En el centro de la "habitación" había un taburete de madera donde me senté.

Gloria me pidió quitarme los zapatos y desnudarme de la cintura para arriba. Pasó tres huevos por mi rostro, pecho y estómago, mientras murmuraba unos rezos ininteligibles. Luego rompió los huevos, depositó el contenido en una bolsa y observó con detenimiento. Me recomendó que tenía que alejarme de la gente que me tenía envidia. Me sobó el pecho y la espalda con una pasta de hierbas y luego me pasó un haz de ortigas. Sacó de su mandil una botella de plástico con "puntas"2, tomó un sorbo y luego me "sopló" el rostro y 
el pecho. Para finalizar me dio una pequeña copa de vidrio con un líquido verduzco hecho de hierbas y "un poquito de ayahuasca, pero poquito".

Cuando salí del "puesto", Gloria me recomendó nuevamente alejarme de las amistades que me tenían envidia y, aunque en general todo estaba bien conmigo, me dijo que debía regresar cada cierto tiempo para hacerme una "limpia". Llenó una bolsa plástica con algunas hierbas y me indicó sobarme el cuerpo con aquello por cuatro días. A continuación entró mi compañera y, según me comentó, tuvo una terapia similar a la mía. Nos fuimos del mercado comentando, con algo de escepticismo, que jamás habríamos imaginado que tendríamos una "limpia", que a lo sumo esperábamos comprar alguna hierba para tomar como infusión. Más tarde ese día conversamos por teléfono y ambos estábamos sorprendidos: el dolor había desaparecido por completo.

Más allá de la anécdota de la experiencia personal, esta medicina llamó mi atención por el lugar donde se desarrollaba: los mercados en la capital de Ecuador. ${ }^{3}$ Con esto no afirmo que solo existan allí, pues varias ciudades sudamericanas albergan una diversidad de tradiciones médicas locales, entrelazadas con la historia del origen de las urbes y la propia salud pública. Sin embargo, Quito en particular tiene una relación especial con las hierberas, pues su actividad se considera como patrimonio de la ciudad y forma parte de los recorridos turísticos de la ciudad.

\section{Los orígenes de la medicina popular en la ciudad}

Las colonias en América enfrentaron el problema del escaso desarrollo de su medicina pública, motivo por el cual las medicinas indígenas continuaron atendiendo por igual a indígenas y españoles a pesar del proceso de "extirpación de idolatrías". Sin embargo, se reconocía las propiedades de las hierbas de los indígenas y su popularidad llegó a oídos del Rey Felipe II, quien comisionó al galeno Francisco Hernández un estudio que se publicó en 1577 bajo el nombre De historia plantarum, animalium et mineralium Novae Hispanae. El entusiasmo por la herbolaria indígena era tal que el doctor Monzo de la Huerta dijo “(...) en este reino hay muchas hierbas medicinales para muchas enfermedades y heridas, las cuales conocen mejor los indios que los médicos, y con ellas se cura mejor que con los remedios médicos" (citado por Hermida 2009, 77).

Quito tuvo un precario sistema de salud en la época colonial. Recursos humanos y económicos limitados, una deplorable enseñanza de medicina sin maestros calificados, poca innovación científica y eran insuficientes 3 En Quito existen va-
rios mercados, sin em-
bargo, concentré mi
trabajo de campo en los
mercados San Roque,
Central, San Francisco
(en el centro de Quito)
y Santa Clara (Norte
central). 
4 En el ámbito de las medicinas, Menéndez (2009) distingue entre las representaciones o formas de percibir, categorizar y dar significado a la salud y las enfermedades; y las prácticas que son aquellos procedimientos, acciones y agentes necesarios para hacer desaparecer la enfermedad y la condición de enfermo. sus características. El año 1786, cuando se reabrió el seminario San Luis, el marqués de Miraflores dijo: "(...) carecemos de copia de profesores de medicina. Quito ha tenido, y aún tiene, uno u otro de talentos ventajosos en esta facultad verdaderamente abstrusa, pero uno u otro no basta para toda la extensión de la provincia. De aquí viene que una ciencia que necesita tantas luces para serlo, se practique comúnmente por mujeres piadosas que vanamente persuadidas a que bastan los buenos deseos para los buenos efectos, matan empíricas con serenidad, y comulgan devotamente por los muertos, a quienes privaron por su ignorancia del amable tesoro de la vida" (citado en E. Estrella, 2004: 227).

Ante esta situación, las autoridades quiteñas respondieron organizando eventos como las romerías para detener a las enfermedades, aunque se toleró la presencia de curanderos indígenas y de su herbolaria, la misma que se utilizó con frecuencia hasta inicios del siglo XIX (R. Estrella 2013, 54). Mientras tanto, los médicos coloniales no podían actualizar sus conocimientos sobre medicina, pues las noticias sobre nuevas terapias llegaban con poca frecuencia desde la metrópoli. Fue recién durante la época republicana que el sistema de salud público experimentó cambios, aunque limitados, debido a la mayor difusión de la medicina positivista europea en las universidades americanas y sobre todo porque el Estado ecuatoriano decidió asumir la responsabilidad por la salud de la población en lugar de los terceros (como la iglesia).

Las medicinas indígenas circulaban en Quito desde su fundación gracias a los barrios habitados por indios. Empleados como fuerza de trabajo para servir a la población blanco - mestiza o para construir infraestructura pública, los migrantes establecieron mercados donde se comercializaban productos que llegaban de las haciendas. De esta forma, no es de extrañar que a Quito llegasen diversas concepciones sobre salud y enfermedad junto a los grupos de migrantes. Esta situación ocurre hasta hoy, puesto que barrios como San Roque y su mercado (donde enfoqué mi investigación) continúan como lugares de acogida de los flujos migratorios de indígenas y no indígenas.

Ahora bien, las medicinas indígenas en la ciudad adquirieron nuevas prácticas y representaciones sobre la salud y la enfermedad. ${ }^{4}$ Quito fue una ciudad donde coexistieron una diversidad de tradiciones médicas indígenas debido a la migración, aunque la llegada de migrantes extranjeros también hacía que circularan otros conocimientos. Estrella (2013) resalta que en Quito surgió una medicina popular urbana que fusionó aspectos de la medicina indígena 
con la medicina española, la misma que centró sus cuidados en las clases bajas mediante una diversidad de especialidades como yerbateros, barberos o sangradores, algebristas o hueseros, herbolarios y comadronas.

Quito, así como otras ciudades, poseen medicinas populares con características propias porque se desarrollaron en espacios urbanos desde su fundación. El dinamismo de las ciudades por su crecimiento poblacional, sus procesos económicos y el desarrollo de infraestructura son factores que configuran la identidad de estas medicinas. En mi caso de estudio, esta medicina popular urbana tiene como elemento de su identidad que es desarrollada por mujeres para quienes no solo es una forma de ganarse la vida, sino que les permite transmitir un acervo de conocimientos sobre cuidados a otras generaciones.

\section{La carta perdida: la interculturalidad en salud y la medicina popular urbana.}

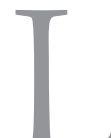

as medicinas indígenas y la herbolaria jugaron un rol importante para la salud de la Colonia, situación que continuó durante los primeros laños de las nuevas repúblicas. Los sistemas públicos de salud y la biomedicina ${ }^{5}$ tuvieron un lento desarrollo por la falta de recursos públicos y humanos. Ecuador, por ejemplo, experimentó una restructuración del Estado de 1895 con la llegada de los liberales al poder, a partir de ese momento tomó medidas para mejorar su sistema de salud público, como crear infraestructura y extender la cobertura al área rural. De esta forma, recién a inicios del siglo XX hubo innovación tecnológica y se insertó en procesos globales de salud (R. Estrella, 2013).

El siglo XX significó cambios en materia de derechos indígenas reflejados en el Convenio 107 de la Organización Internacional del Trabajo (OIT) de $1957 .{ }^{6}$ La década de los 70 trajo además la discusión de nuevos derechos, de tercera generación, y a finales de la década de los años 80 el Convenio 169 de la OIT sirvió como un instrumento más para las reivindicaciones indígenas. En este contexto, las medicinas tradicionales cobraron interés para los Estados en el año 1978, cuando la Conferencia de Alma Ata discutió su rol en los sistemas públicos de salud. La Conferencia recomendó que los medicamentos herbolarios se integren a las políticas de salud, aunque cumpliendo los reglamentos farmacéuticos, criterios científicos, estándares y la normativa internacional.

En los siguientes años la promoción de la medicina tradicional a nivel global continuó, por ejemplo, con la $40^{\circ}$ Asamblea General de la Organización
5 La Real Academia Española define biomedicina como medicina clínica basada en las ciencias naturales (biología, física, química, etc.)

6 Disponible en http:// oas.org/dil/esp/afrodescendientes_instrumentos internacionales_convenio_107.pdf 
7 OMS (2013) Estrategia de la OMS sobre medicina tradicional 2014 - 2023. Ginebra Suiza: Organización Mundial de la Salud. El documento puede ser descargado en http:// apps.who.int/medicinedocs/es/m/abstract/Js21201es/
Mundial de la Salud (OMS) de 1987, donde se recomendó hacer estudios de identificación, evaluación, preparación, cultivo y conservación de las hierbas utilizadas por la medicina tradicional. También se recomendó controlar de calidad de los medicamentos derivados de plantas, mediante estándares adecuados y buenas prácticas de fabricación. Estos acuerdos y los que vendrían estimularon para que la OMS redacte lineamientos para integrar a las medicinas indígenas en los sistemas públicos de salud.

Uno de los más notables ejemplos del interés por las tradiciones médicas es el documento "Estrategias de la OMS sobre medicina tradicional" que busca brindar a "instancias normativas, los planificadores del servicio de salud, especialistas de salud (...) información, contexto, orientación y apoyo en lo concerniente a las medicina tradicional y complementaria, incluidos sus productos, prácticas y profesionales". Además, "(...) ayudar a los Estados miembro a desarrollar políticas dinámicas y aplicar planes de acción que refuercen el papel de la medicina tradicional en el mantenimiento de salud de las personas" ${ }^{\prime 7}$.

Mientras tanto, el debate sobre la convivencia de culturas también se desarrolló. En Europa surgió la discusión debido a las olas migratorias del África, Latinoamérica y del interior de la propia Europa, mientras que en América Latina brotó junto al levantamiento indígena de Chiapas de 1994. Estos cuestionamientos, acompañados por movilizaciones de los pueblos indígenas, lograron reformas sociales, políticas y jurídicas. De esta manera, se cuestionó la idea de nación única, contraponiendo la plurinacionalidad que luego se orientó hacia construir una sociedad intercultural.

En el Ecuador el término interculturalidad surgió en la década de los años 80, impulsado por el movimiento indígena que reivindicó reformar la educación y con ello las estructuras del Estado. Walsh (2012) indica que la interculturalidad fue un proyecto político que nació de la reflexión de los indígenas ecuatorianos y no en la academia, las ONG o el Estado (Walsh, 2012: 103). En términos de la salud, comenzó a hablarse de salud intercultural a partir de las reformas constitucionales de 1998 y luego con la Constitución de 2008 que dio paso a toda una serie de ajustes jurídicos.

\section{La interculturalidad en salud se despolitiza}

El significado del término interculturalidad es elusivo, aunque en general hace referencia a la interrelación, el diálogo y las relaciones de respeto entre 
diversas culturas. Afines a esta concepción son palabras como convivencia, coexistencia y tolerancia. Sin embargo, esta idea pretende mostrar una sociedad que convive pacíficamente sin cuestionar la desigualdad, la explotación y dominación (Viaña, 2010: 12). Por lo tanto, pese a que la interculturalidad surgió como proyecto político indígena, cuando es adoptado por el Estado pierde su contenido crítico y es funcional para los grupos dominantes.

La interculturalidad en salud que asumieron muchas organizaciones de desarrollo y los Estados tiene también este enfoque armónico-despolitizado. En nuestros países abundan las experiencias de instituciones públicas y privadas que fomentaron $\mathrm{y} / \mathrm{o}$ impulsaron las medicinas y se integran mediante acciones interculturales. El enfoque utilizado por estos trabajos es totalizador, pues otorga el mismo valor a las representaciones y prácticas de las diversas tradiciones médicas. Sin embargo, este enfoque no toma en cuenta las desigualdades entre las tradiciones médicas respecto a la biomedicina.

El problema de la interculturalidad en salud es que se desarrolla dentro de un modelo médico hegemónico basado en la biomedicina que excluye ideológica y jurídicamente a las otras medicinas. Esto implica que los axiomas y los mecanismos de validación ${ }^{8}$ biomédicos se imponen para determinar cuáles terapias tradicionales son científicas para incorporarse al sistema público de salud. Por ello, las medicinas tradicionales no están en pie de igualdad, sino que son subalternizadas: se determinan que procedimientos son válidos, se regulan sus acciones y descartan los aspectos religioso-simbólicos.

Siguiendo a Modena (1995), podemos indicar que la interculturalidad en salud incorpora a las medicinas tradicionales bajo tres enfoques. El primero es el reconocimiento jurídico que busca que prácticas y terapeutas populares se legitimen, aunque esto no significa que la discriminación, las relaciones de poder y la discriminación desaparezcan. La segunda es la incorporación que implica que se institucionaliza la práctica de combinar los recursos médicos oficiales, privados y populares, aunque su efecto negativo es un mayor control de la biomedicina sobre los recursos terapéuticos disponibles y las terapias tradicionales, sin mencionar que surgen conflictos entre las medicinas por ocupar el mismo espacio físico ${ }^{9}$. La última es la legalización formal que supone ajustes reglamentarios y vigilar las acciones de la medicina, desde y afuera. Esto puede causar mayor burocratización, que se excluyan grupos, corrupción y estamentación.
8 Los axiomas son los principios y las definiciones fundamentales que no requieren pruebas para demostrar su existencia y que resisten todo argumento. Los mecanismos de validación son los hechos y evidencias que comprueban lo que creen los sujetos. Para las medicinas tradicionales, por ejemplo, un axioma sería que hay enfermedades originadas por fuerzas sobrenaturales, mientras que un mecanismo de validación que la enfermedad se manifieste en sueños. Para la biomedicina un axioma es que un resfrío se origina por un virus, mientras que los mecanismos de validación podrán ser los estudios científicos, textos, etc.

9 Esta es la lógica de los partos interculturales. Algunos hospitales públicos habilitan un espacio para las parteras, sin embargo, esta iniciativa no es sistemática, pues no todos los centros hospitalarios poseen el servicio. 
10 http://www.sipi siteal.iipe.unesco.org/ sites/default/files/sipi normativa/ecuador ley_nro_67_2006.pdf 11 Ibíd.
Quiero añadir un cuarto enfoque a la relación Estado-medicina tradicional: la omisión. Mi trabajo de campo en la ciudad de Quito me mostró que la interculturalidad en salud excluye a ciertas medicinas como la de las hierberas. A pesar de que en Ecuador la discusión sobre la cuestión de la salud ha tenido referentes políticos importantes desde la introducción del enfoque de los determinantes sociales de la salud en los años 80, mi trabajo de campo me mostró que la interculturalidad en salud que el Estado maneja parte de una concepción limitada sobre lo que es "tradicional".

El artículo 25 de la Ley Orgánica de Salud del Ecuador en su artículo 25 menciona que el Ministerio de este ramo debe "Establecer políticas para desarrollar, promover y potenciar la práctica de la medicina tradicional, ancestral y alternativa; así como la investigación, para su buena práctica."10. El artículo V da una definición de las medicinas tradicionales:

Son el conjunto de conocimientos y prácticas ancestrales de las nacionalidades, pueblos, comunidades indígenas, mestizas y afro descendientes que a lo largo del tiempo han constituido un saber específico, mantenido y difundido en un contexto cultural, de interrelación de elementos naturales, éticos, espirituales, mentales, psicológicos y afectivos y que se explica y funciona en ese mismo universo cultural. Sus prácticas se corresponden con saberes, técnicas y procedimientos propios de su cosmovisión y son ejercidas por sanadores de las medicinas tradicionales, reconocidos por sus comunidades y registrados por la autoridad sanitaria nacional. (El subrayado es mío) ${ }^{11}$.

Si en el primer caso distinguía entre dos tipos de medicina -ancestral y tradicional- en la definición uno sería constitutivo del otro, pues los conocimientos y prácticas ancestrales pertenecerían a un ámbito extenso de la sociedad. La OMS, principal guía de las políticas de salud de los países, tiene una definición menos precisa aún de la medicina tradicional que sería "la suma total de los conocimientos, capacidades y prácticas basados en las teorías, creencias y experiencias propias de diferentes culturas, bien sean explicables o no, utilizadas para mantener la salud y prevenir, diagnosticar, mejorar o tratar enfermedades físicas y mentales" (OMS, 2013, pág. 15). Sin embargo, se complica aún más cuando habla sobre medicina complementaria: 
Los términos "medicina complementaria" o "medicina alternativa" aluden a un amplio conjunto de prácticas de atención de salud que no forman parte de la tradición ni de la medicina convencional de un país dado que ni están totalmente integradas en el sistema de salud predominante. En algunos países, esos términos se utilizan indistintamente para referirse a la medicina tradicional ${ }^{12}$ (OMS, 2013).

Siguiendo la definición de la Ley Orgánica de Salud, la medicina popular tendría elementos que podrían definirla como ancestral/tradicional, como la práctica herbolaria o las terapias con cuy. Sin embargo, el uso de otras terapias como el uso de velas, esencias e incluso biomedicamentos no estarían dentro de esta categoría y la acercarían más hacia la medicina "complementaria". De esta manera, esta tradición médica se muestra elusiva para encajar en alguna de estas categorías al contar con elementos terapéuticos diversos.

Tenemos así una medicina que representa una paradoja para las políticas públicas de la salud del Ecuador. Si bien es visible e incluso considerada parte del patrimonio y de la identidad de la ciudad de Quito, el Estado y su sistema público de salud no tiene una relación clara al no encajar esta medicina dentro lo "ancestral/tradicional". Durante mi trabajo, comprobé que la Dirección de Salud Intercultural del Ministerio de Salud Pública no tenía ninguna acción específica con la medicina de los mercados y que su trabajo se enfocaba al parto intercultural y las medicinas de las nacionalidades indígenas.

La causa de este olvido aparente se sustenta en que Ecuador y en otros países la interculturalidad en salud es de lograr no conflictividad entre medicinas. Esta armonía quiere justificarse promoviendo un diálogo entre "diferentes", basada en el respeto y la igualdad, para lograr la inclusión, simetría y equidad. La medicina popular urbana no cumpliría con esta condición al representar en sí misma un conflicto entre lo tradicional y lo no tradicional, tensión que resuelve ajustando sus representaciones sobre salud y enfermedad a las nuevas prácticas incorporadas.

Esta situación reflejaría que: “(...) la institucionalidad oficial acepta el "valor" de las terapias ancestrales, las asume, pero las inscribe y subordina a la lógica dominante que está muy influida por el modelo biomédico alopático. Y entonces vivimos la contradicción de que celebramos la incorporación de estas terapias alternativas, pero no nos percatamos de que su modo de incorporación las limita y desnaturaliza." (Breilh, 2010: 23).

12 El subrayado es mío. 
En Quito encontramos diversas medicinas populares urbanas, entre ellas la que decidí estudiar en los mercados de Quito. Esta, junto a otras, atiende las necesidades de salud de la población a diario, necesidades específicas que no siempre pueden ser atendidas por el sistema público de salud. Sin embargo, esta medicina no tiene relación con las políticas estatales de interculturalidad e incluso opera en los límites, una "zona gris". Este espacio, como mostraré a continuación, le permite desarrollarse, innovar y resistir a los intentos de homogeneización de la interculturalidad en salud estatal.

\section{La "zona gris" de la interculturalidad en la salud}

1 l concepto de "medicina popular" (Folk medicine) surgió a fines del siglo 1 XIX y principios del XX con autores como George W. Black, Giuseppe Piré J Joan Amades. Para ellos, las tradiciones médicas eran "sobrevivientes" o "remanentes" de los grupos sociales. En los años 70, Irwin Press (1978) habló de una "medicina popular urbana" (Urban folk medicine) para señalar que en sociedades no-industriales o no-occidentales existían conceptos y prácticas de salud y enfermedad que constituían sistemas abiertos (la biomedicina era uno cerrado), los cuales se adaptaban e incorporaban nuevos elementos a sus estructuras para ajustarse a la ciudad. (Press, 1978: 72).

Planteo que el concepto de salud popular urbana debe repensarse porque sirve para entender a las tradiciones médicas que se desarrollan en la ciudad. Primero, porque esta noción hace referencia a su dinamismo y capacidad de transformarse: "Los curadores se diversifican en estilo y especialización para satisfacer las necesidades de una población más heterogénea" (Press, 1978: 75). En mi caso de estudio esto significa, por ejemplo, el uso de productos esotéricos (velas, perfumes, esencias) a las terapias que, según pregunté a las hierberas, son de incorporación recientes (algunas me hablaron de diez o quince años) y proceden de países como Perú y Colombia.

Segundo, porque las representaciones sobre las enfermedades también se transforman para albergar un mayor espectro de lo que es perjudicial para el cuerpo. Press (1978) además indicaba que las prácticas de la medicina popular perduran incluso cuando el concepto de enfermedad popular ya no existe (72). Un ejemplo es que las hierberas utilizan terapias para aliviar enfermedades que se consideran "modernas" como el cáncer o el colesterol. Como recordará el lector, cuando tuve mi primera experiencia con esta medicina se me diagnosticó estrés y para tratarlo me hicieron una "limpia". 
Un tercer argumento es revisar el vocablo "popular" no solo para particularizarla frente a la ambigüedad de lo "tradicional" y lo "ancestral", sino también para reflejar la idea de resistencia. Esto supone eludir las dicotomías "lo culto" y "lo popular" que la reducen a lo raro, lo exótico y lo mágico. Más bien, "lo popular" debe entenderse como adjetivo que procede del término "pueblo" y que se refiere a sus saberes (Bejarano, 2004: 16). También como concepto para designar una forma de ver, pensar y experimentar la realidad culturalmente aprendida.

Dicho sistema cognitivo no son estructuras preexistentes e impuestas al sujeto, sino que son determinadas por la agencia, la cual debemos entenderla tanto como subjetividad como por resultado de las intersubjetividades: "cada sujeto es y actúa en la medida en que vive (es y actúa) con otras y otros en momentos históricos específicos" (Abadía-Barrero y Oviedo-Manrique, 2008: 74). "Lo popular", como visión de mundo construida por un sujeto que interactúa con otros, permite comprender que las "medicinas populares" son "núcleos ideológicos de cuestionamiento, resistencia y hasta enfrentamiento a las prácticas hegemónicas" (Bejarano, 2004: 16).

\section{La zona gris: espacio de resistencia en las fronteras}

Que las medicinas populares puedan cuestionar, resistir y enfrentarse a un modelo médico hegemónico, basado en la biomedicina, solo es posible porque se desarrollan en una "zona gris". Este concepto fue acuñado por Primo Levi en $1986^{13}$ y retomado recientemente por Javier Auyero para evitar "dicotomías demasiado rígidas" (Auyero, 2007: 54). En mi caso, deseo aplicarlo para indicar un espacio de excepción, un interregno delimitado por límites espaciales y simbólicos donde las medicinas populares urbanas tienen la posibilidad de desarrollarse; logrando al mismo tiempo resistir al modelo hegemónico promovido por las políticas de interculturalidad en salud estatales.

Las fronteras físicas son establecidas por la ciudad que subordina estas medicinas a determinados espacios en su interior. Por ejemplo, en mi estudio de caso la medicina de las hierberas está adscrita a los mercados y sus zonas aledañas, ${ }^{14}$ mas no a los espacios a los que debería pertenecer de acuerdo a la interculturalidad en salud: los centros de salud. Las fronteras físicas para la medicina de las hierbas no son casuales, pues los mercados donde se asientan tradicionalmente se encuentran en una zona que albergó a indígenas desde la fundación de Quito. Como indiqué, el barrio y el mercado San Roque continuán recibiendo a migrantes que buscan mejores oportunidades en la capital.
13 Levi utilizó este concepto para narrar su aberrante experiencia en un campo de concentración nazi. Que utilice el término para mi investigación no significa que quiera banalizarlo al sacarlo de contexto. Mi intención, al igual que Auyero, es rescatar la relevancia metodológica del concepto.

14 Las hierbas medicinales también se venden en calles y locales. 
Esta frontera física alberga a un sector concreto de la población: las mujeres. El trabajo de la mujer en el sector informal de la economía esta subvalorado y es más precario que el del hombre en este mismo sector. Las mujeres perciben remuneraciones más bajas, sus actividades económicas se consideran parte de sus obligaciones domésticas y familiares. Sin embargo, su presencia en el sector informal no es casual, pues da mayor facilidad para ingresar que el formal. Además, les posibilita obtener ingresos económicos, logrando visibilidad y reconocimiento social.

Cuminao (2012) observa que en el mercado San Roque de Quito hay una división sexual del trabajo que asocia a las mujeres las actividades como la venta, la manipulación de alimentos, el trabajo doméstico y las actividades litúrgicas y de fiestas. Sin embargo, esto implica que deben desplegar estrategias de subsistencia y apropiación del espacio (83). Mi trabajo de campo me mostró aquello: el oficio de hierberas permite a que estas mujeres aporten a la economía familiar, que muchas veces depende exclusivamente de ellas. Con esta labor transmiten también sus conocimientos sobre medicina. Así, los límites físicos de una zona gris permiten contar con un espacio de influencia en la comunidad y contribuir a la economía familiar.

Como señalé antes, las políticas públicas de interculturalidad en salud se desarrollan y se orientan bajo un modelo médico hegemónico que impone los axiomas y mecanismos de validación de la biomedicina a las medicinas tradicionales. De esta forma, solo algunas de sus prácticas son aprobadas por considerarse científicamente válidas, mientras que otras, incluyendo a sus representaciones, son dejadas de lado. El Estado despliega así uno de sus tres enfoques (reconocimiento, incorporación y legalización) para que la biomedicina determine que elementos formarán parte del sistema público de salud.

Sin embargo, propuse un cuarto enfoque que es la omisión. Los límites simbólicos de la zona gris se expresan cuando algunas tradiciones médicas, como las medicinas populares urbanas, son omitidas. Las medicinas "ancestrales" o "tradicionales", identificadas con algún pueblo indígena y rural, se consideran sujetos de la interculturalidad en salud, mientras que otras están ausentes del marco normativo porque combinan sus representaciones y prácticas con otra tradiciones. Esto sucede porque se consideran entidades estáticas, sin cambios, que no utilizan terapias médicas de otras medicinas. 
En el caso de las hierberas de los mercados de Quito, constaté que su ambigüedad para considerarlas como "ancestral/tradicional" incluso podría traer consecuencias. Los "puestos" están dentro de los mercados y se las considera como cualquier otro comerciante, por lo tanto se rigen por las normas del mercado como cualquier otro comercio. Sin embargo, las especificidades de su labor, las representaciones y prácticas, no son tomadas en cuenta y la normativa del mercado puede incluso llegar a perjudicarles por su poca claridad. ${ }^{15}$

Las fronteras simbólicas se expresan también en la ambigüedad para valorarla. A menudo se condena a la medicina popular urbana por algunas de sus representaciones y prácticas desde visiones religiosas por considerarlas contrarias a la religión católica. Por ejemplo, en mi trabajo de campo a menudo escuché que se les acusaba por hechicería. De hecho, las hierberas tienen mucho cuidado en aclarar a sus pacientes que su curación está guiada sobre todo por el Dios católico. Por ello, no debe extrañar que los espacios donde realizan su trabajo esté lleno de imágenes católicas, como narré en mi experiencia.

También hay opiniones que minusvaloran a las medicinas populares urbanas llamándolas supersticiones o incluso timos. Esta valoración se centra en las representaciones y en prácticas concretas. Por ejemplo, en mi estudio de caso uno de los temas más complejos fue la "limpia" con cuy, cuestionada por su utilidad e incluso por el trato que se da al animal. En todo caso, las hierberas a menudo se defienden de la incredulidad diciendo que se un paciente sin fe solo provocará que su terapia no tenga ningún resultado.

Un último límite simbólico se da en el ambito de lo médico. La medicina popular urbana a menudo tiene cobertura mediatica y forma parte de la identidad de la ciudad. Sin embargo, aquello obscurece su aporte a la salud de la población, pues la limita a la tradición, por lo tanto, se folkloriza a estas medicinas. En Quito las hierberas reciben atención de los medios, ${ }^{16}$ son parte del circuito turístico y reconocidas como patrimonio cultural. Sin embargo, su rol como dentro del sistema sanitario de la ciudad queda a menudo desdibujado a favor de lo folklórico.

Los límites espaciales y simbólicos de la zona gris dan un margen a la medicina popular urbana para reproducirse, vincularse con otras tradiciones médicas y para organizarse. En el caso de la medicina con hierbas de los mercados de Quito no solo se trata de que estas mujeres transmiten los conocimientos
15 Durante mi trabajo de campo hallé la Ordenanza Metropolitana 0253 cuyo artículo 29 , inciso i, menciona que la suspensión temporal ocurre por "Practicar ritos, magia o hechicería en el puesto o en las instalaciones del mercado, exceptuándose las prácticas de medicina natural en puestos autorizados para el efecto". Los funcionarios municipales no pudieron aclararme qué se considera como hechizo, magia y los ritos.

16 Ver por ejemplo esta nota del diario El Comercio: http://patrimonio.elcomercio. $\mathrm{com} /$ patrimonio-contemporaneo/las-limpias-de-san-francisco/ historia \#. WLCQ5 RCr_OO 
17 Una hierbera me indicó que a veces, cuando no conocía mucho sobre alguna enfermedad, pedía a sus hijos que le ayuden buscando información por internet.

18 Acompañé a una hierbera a un ritual curanderil en el norte de Quito. Este curandero hacia los "soplos" y también las "limpias", pero su trabajo era romper los hechizos de la gente que concurrió aquella noche.

19 En el mercado San Roque las dos hermanas Chicaiza son las únicas que hacen la "limpia" con cuy. Una de las hierberas quiso hacer la "limpia" con cuy e inmediatamente las dos hermanas denunciaron a la mujer al administrador, quien aceptó la queja porque reconoció que ellas son las únicas calificadas para hacerlo. a su descendencia, sino que incorporan nuevos saberes continuamente. Las hierberas amplían sus representaciones sobre la enfermedad (por ejemplo, el estrés, cáncer, etc.), pero también sus prácticas curativas a través de aprender elementos de otras medicinas ${ }^{17}$. Por ello, el uso de terapias de otras tradiciones, incluso de algunos elementos de la biomedicina, es usual. Las hierberas entonces no solo reciben, sino también producen conocimiento sobre cuidado.

La zona gris también es un espacio de vínculo, de interrelación. A menudo las medicinas populares urbanas se relacionan con otras, particularmente la biomedicina. Las hierberas de los mercados envían a sus pacientes al biomédico cuando consideran que no tienen competencia sobre la enfermedad o para complementar la curación, por ejemplo, indicando que se necesita una radiografía o algún análisis. Sin embargo, también mantienen relación con otros curadores de saberes específicos. En los mercados podemos hallar parteras y "sobadores" que no utilizan su conocimiento como primera actividad economica, sino que son comerciantes que ejercen sus habilidades cuando se les requiere. Las hierberas acuden también muy a menudo a consultar a curanderos que deshacen hechizos, porque ellas no siempre tienen estos conocimientos especializados. ${ }^{18}$

Por último, la medicina urbana popular en la zona gris tiene capacidad de modificar su organización ante la presencia ambigua del Estado. Por ejemplo, en los mercados de Quito las hierberas autorregulan el costo y quién puede realizar las terapias, al menos dentro de cada mercado. Existe cierta sancion social cuando alguna pretende cobrar precios más caros al público, porque la lógica es que eso hará que los clientes vayan a otro mercado donde cobren más barato. De la misma manera, no cualquiera puede hacer una "limpia" y menos aún con cuy, porque las mujeres suelen reclamar que toda persona que haga una terapia debe tener la competencia para hacerlo. ${ }^{19}$

\section{Conclusiones}

ichel De Certau destacaba que la creatividad humana se despliega
en lo cotidiano, evitando la vigilancia. Si Foucault insistía en
dispositivos minúsculos para asegurar el poder, De Certau lo hacía con los procedimientos populares diminutos que resisten la disciplina impuesta, es decir, toda "manera de hacer [que] constituyen las mil prácticas a través de las cuales los usuarios se reapropian del espacio organizado por los técnicos de la producción sociocultural." (De Certau, 2010: 44). Para este autor, en la ciudad se despliegan estas prácticas dentro las propias redes de vigilancia. 
James C. Scott (2000) afirmó también que en cualquier estructura de dominación surgen procesos de resistencia. Estos surgen de forma clandestina, como tácticas y estrategias para resistir a la dominación. De esta manera, los grupos subordinados producen discursos ocultos que se oponen al dominador, tienen una "resistencia discreta" que les permite conservar el anonimato (Scott, 2000: 42). Es en suma, una "infrapolítica de los desvalidos" (Scott, 2000: 21). Las zonas grises de la medicina son precisamente estos espacios que aluden De Certau y Scott. Comencé este texto comentando el cuento de Poe "La carta robada" para usarla como metáfora. En este sentido, la interculturalidad en salud del Estado se contituye en la policía parisina que tiene frente a sí la carta (la medicina popular urbana), pero no la encuentra. En el cuento de Poe los policías no tenían las habilidades para encontrarla, aunque también podría tratarse de un acto deliberado para no perjudicar al ladrón, un reconocido político francés. En todo caso, la narrativa de Poe no nos presenta el punto de vista de los policias, sus motivaciones.

En el caso de la interculturalidad en salud en este texto intenté mostrar que sí hay una omisión deliberada de la medicina popular urbana. Una primera causa está en que la definición de medicina "ancestral", a veces designada indistintamente como "tradicional", guarda cierta ambigüedad que dificulta establecer si la medicina popular urbana es parte de ella, puesto que esta no solamente tiene elementos terapeúticos "ancestrales" sino que adquiere otros nuevos. Además, las políticas de interculturalidad en salud buscan establecer una situación no conflictiva entre medicinas, frente a lo cual la medicina popular se establece como conflictiva por no ser del todo "ancestral".

La interculturalidad como proyecto estatal es vaciada de su contenido político y funcionalizada para incorporarse a su hegemonía. En el ámbito de la salud en particular se desarrolla bajo un modelo médico hegemónico biomédico que impone sus axiomas y mecanismos de validación a otras tradiciones médicas. Dentro de esta perespectiva, se espera que las medicinas mantengan unas relaciones idílicas de convivencia armónica, aunque en la práctica la biomedicina las regule.

La interculturalidad en salud opera así como una "razon metonímica" (Dos Santos, 2007) que pretende correspondencia entre el todo y las partes, donde lo que esta fuera de esa totalidad no tiene existencia. Esta totalidad se intenta mostrar como horizontal, libre de jerarquías, pero oculta dicotomías jerarquizadas: cultura científica/cultura tradicional, hombre/mujer, civilizado 
primitivo, etc. (Dos Santos, 2007: 70). Trouillot indicaba del peligro de que la proximidad del Otro se presente como signo de diversidad, en tanto quien defina la calidad de las relaciones sea quien no es este Otro, es decir, los individuos o grupos que no están categorizados en una alteridad definen la forma, naturaleza y significado del contacto con el Otro (141). Este es el caso de la interculturalidad en salud donde la biomedicina se arroga el derecho de establecer el tipo de relaciones que sostendrá con las Otras medicinas dentro del sistema público de salud.

Sin embargo, sostengo que las zonas grises donde se desarrollan las medicinas populares urbanas se constituyen en espacios de resistencia a esta relación asimétrica, como en el caso de la medicina de hierbas en los mercados quiteños. La resistencia presente allí es subrepticia, no es violenta, pues aquello no haría más que visibilizar la zona gris y esta se perdería irremediablemente. Se trata más bien de nuevas formas, no tradicionales, que los "débiles" tienen para expresar su poder.

La atención de la medicina popular urbana se desarrolla por ello en unos límites donde le es posible reproducir saberes tradicionales a los que va agregando otros de otras tradiciones médicas, incluso de la biomedicina. También se hace posible un espacio de interrelación con otras medicinas, insertándose así en las etapas curativas que cada paciente realizará para atender su salud. Finalmente, ante la presencia poco clara del Estado, se organizará para regular algunos aspectos de su práctica profesional, alejando así la intervención estatal. Con todo ello, la ausencia de la interculturalidad en salud se convierte en una oportunidad para su desarrollo y preservación.

\section{REFERENCIAS BIBLIOGRÁFICAS}

Abadía-Barrero, C. E. \& Oviedo-Manrique, D. G. (2008, julio-diciembre). Intersubjetividades estructuradas: la salud en Colombia como dilema epistemológico y político para las ciencias sociales. Universitas Humanistica (66), 57-82.

Auyero, J. (2007). La zona gris: Violencia colectiva y política partidaria en la Argentina contemporánea. Buenos Aires, Argentina: Siglo XXI Editores.

Bejarano, I. (2004, julio). Lo culto y lo popular. Medicina letrada/medicina tradicional. Hacia una práctica unificada de los conocimientos médicos. Cuadernos de la Facultad de Humanidades y Ciencias Sociales (24), 13-22.

Breilh, J. (2010). Lo etnocultural en la determinación de la salud. Entrevista con Jaime Breilh (realizada por Ylonka Tillería) . Revista Anaconda internacional, 25(4), 19-23. 
Cuminao, C. (2012). Construcción de las identidades de las vendedoras Kichwas y mestizas y los juegos de poder en el mercado San Roque. In E. Kingman G., San Roque: indígenas urbanos, seguridad y patrimonio (pp. 79-100). Quito, Ecuador: Flacso - Heifer Internacional.

De Certau, M. (2010). La invención de lo cotidiano. 1: Artes de hacer (Vol. I). México, México: Universidad Iberoamericana.

Dos Santos, B. (2007). Conocer desde el sur. Para una política emancipatoria. Lima, Perú: Programa de Estudios sobre Democracia y Transformación Global, Fondo Editorial de la Facultad de Ciencias Sociales/Unidad de Post Grado.

Estrella, R. (2013). Breve historia de la medicina del Ecuador. Quito, Ecuador: Casa de la Cultura Ecuatoriana.

Hermida, C. (2009). Obras completas: medicina intercultural (Vol. VII). Quito, Ecuador: Conesup, UTE.

Menéndez, E. (2009). Modelos, saberes y formas de atención de los padecimientos: de exclusiones ideológicas y de articulaciones prácticas. In L. Citarella, \& A. Zangari, Yachay Tinkuy. Salud e interculturalidad en Bolivia y América Latina (pp. 87-126). Bolivia: Prohisaba, Cooperación Italiana, Editorial Gente Común.

Modena, M. E. (1995). Reconocimiento, incorporación, legalización: algunos riesgos de la hegemonización del pensamiento y la acción respecto a las medicinas populares. In V. Chenaut, \& M. T. Sierra, Pueblos indigenas ante el derecho (pp. 221-230). México DF, México: CIESAS.

Press, I. (1978, Marzo). Urban folk medicine: A functional overview. American Anthropologist, $80(1), 71-84$

Scott, J. C. (2000). Los dominados y el arte de la resistencia. México, México: Ediciones Era.

Trouillot, M. R. (2011). Transformaciones globales. La antropología y el mundo moderno. Popayán, Colombia: Universidad del Cauca, CESO-Universidad de los Andes.

Walsh, C. (2012). Interculturalidad, plurinacionalidad y razón decolonial: refundares políticoepistémicos en marcha. In R. Grosfoguel, \& R. Almanza H., Lugares descoloniales: espacios de intervención en las Américas (pp. 95-118). Bogotá, Colombia: Pontificia Universidad Javeriana. 